Original Article

\title{
Effect of body awareness training on balance and walking ability in chronic stroke patients: a randomized controlled trial
}

\author{
Dae-Hyouk Bang, PT, MSc ${ }^{1)}$, Hyuk-Shin Cho, PT, $\left.\mathrm{PhD}^{2}\right)^{*}$ \\ 1) Department of Physical Therapy, Graduate School of Daejeon University, Republic of Korea \\ 2) Department of Physical Therapy, Wonkwang Health Science University: 514 Sinyong-dong, Iksan-si, \\ Jeollabuk-do 570-750, Republic of Korea
}

\begin{abstract}
Purpose] To investigate the effects of body awareness training on balance and walking ability in chronic stroke patients. [Subjects] The subjects were randomly assigned to a body awareness training group ( $\mathrm{n}=6$ ) and a control group $(n=6)$. [Methods] Patients in the body awareness training group received body awareness training for 20 minutes, followed by walking training for 30 minutes a day, 5 days a week for 4 weeks. The control group received walking training for 30 minutes a day, 5 days a week for 4 weeks. [Results] After the intervention, both groups showed significant improvements in the Berg Balance Scale, Timed Up and Go Test, and $10 \mathrm{~m}$ walk test compared with baseline results. The body awareness training group showed more significant improvements in the Berg Balance Scale and Timed Up and Go Test than the control group. There was no significant difference in the $10 \mathrm{~m}$ walk test between the groups. [Conclusion] The results of this study suggest that body awareness training has a positive effect on balance in patients with chronic stroke.

Key words: Balance, Body awareness, Walking
\end{abstract}

(This article was submitted Sep. 30, 2015, and was accepted Oct. 14, 2015)

\section{INTRODUCTION}

Impairement of postural control ability is common in patients with stroke ${ }^{1)}$. Decreased postural control ability is a major risk factor for falls ${ }^{2)}$. Patients with stroke often show asymmetric standing balance, which affects stability limits, and can cause difficulty in recovery of functional independence ${ }^{3}$. Impaired postural control ability is a barrier to improvement of balance and walking ability for independent living in patients with damage to the central nervous system ${ }^{4}$. Gait disruption not only limits independent living for stroke patients, but also puts them at risk for fall-related injuries and for development of secondary impairments ${ }^{5)}$. Thus, a primary goal in stroke rehabilitation is to improve walking ability ${ }^{6}$. Balance ability is a major factor in improvement of walking ability ${ }^{7,8)}$. Thus, many therapeutic approaches that aim to improve postural control in stroke patients have been investigated. This training can be provided using different methods and contents, but should have a task-specific approach ${ }^{9)}$.

Body awareness training (BAT) is a method for improvement of dynamic balance and postural control ability. BAT is comprised of simple repetitive movements that maintain ability using stability limits ${ }^{10}$. A main component of BAT is to enhance an individual's awareness of their movement ${ }^{11}$. Multiple slow repetitive movements may enable the participant to experience the body and its limits. In other words, BAT generates awareness of one's body and enables focus on body awareness during movement. Movements are performed in various positions in order to identify the center line of the body. BAT results in improved postural control, balance, free breathing, and coordination ${ }^{3)}$.

It has been suggested that BAT could be beneficial for improving balance in stroke patients ${ }^{4}$. However, there are no

\footnotetext{
*Corresponding author: Hyuk-Shin Cho (E-mail: hscho90@hanmail.net)

(C) The Society of Physical Therapy Science. Published by IPEC Inc.

This is an open-access article distributed under the terms of the Creative Commons Attribution Non-Commercial No Derivatives (by-nc-nd) License $<$ http://creativecommons.org/licenses/by-nc-nd/3.0/>.
} 
Table 1. General characteristics of the subjects

\begin{tabular}{lcc}
\hline & $\begin{array}{c}\text { Experimental group } \\
(\mathrm{n}=6)\end{array}$ & $\begin{array}{c}\text { Control group } \\
(\mathrm{n}=6)\end{array}$ \\
\hline Gender & & \\
Male/Female & $3 / 3$ & $4 / 2$ \\
Paretic side & & \\
Right/Left & $4 / 2$ & $3 / 3$ \\
Age (years) & $63.7 \pm 7.1 *$ & $64.6 \pm 5.9$ \\
Weight (kg) & $65.4 \pm 4.8$ & $66.8 \pm 7.2$ \\
Height (cm) & $163.8 \pm 6.3$ & $164.7 \pm 5.6$ \\
Duration (weeks) & $23.5 \pm 5.6$ & $21.8 \pm 7.3$ \\
\hline *Mean \pm SD & &
\end{tabular}

reported studies on the effects of BAT on balance and walking ability in chronic stroke patients. Therefore, the purpose of this study was to investigate the effects of BAT on balance and walking ability in chronic stroke patients using the Berg Balance Scale (BBS), Timed Up and Go Test (TUG), and $10 \mathrm{~m}$ walk test (10MWT).

\section{SUBJECTS AND METHODS}

The subjects were 12 post-stroke patients admitted to the rehabilitation center of a university hospital in the Republic of Korea. They were randomized into two groups by a person not involved in the study. The experimental group performed BAT, followed by walking training; BAT was performed for 20 minutes. The control group performed walking training only. Randomization was performed by selection of opaque closed envelopes containing the group assignment. The inclusion criteria were: (1) history and clinical presentation (hemiparesis) of stroke (first hemorrhage or infarction); (2) event occurring > 6 months previously; and (3) ability to walk a distance of 100 meters with or without assistance. The exclusion criteria were: (1) the presence of any comorbidity or disability other than stroke that would preclude gait training, or (2) any uncontrolled health condition for which exercise was contraindicated.

Participation was voluntary, and the subjects fully understood the study. Written informed consent was obtained from all subject after an explanation of the study purpose and the experimental method and processes were provided. The study was approved by the institutional review board of Daejeon University and followed the principles outlined in the Declaration of Helsinki.

A four-week training study was designed to evaluate the effect of BAT on balance and walking ability in chronic stroke patients.

The Berg Balance Scale (BBS) was used as a general balance test ${ }^{12}$. This scale consisted of 14 balance activities, ranging from sit-to-stand to standing on one leg.

The Timed Up and Go Test (TUG) was used as a dynamic balance test ${ }^{13}$. This test records the time taken to rise from a chair (height: $50 \mathrm{~cm}$ ), walk $3 \mathrm{~m}$, turn around a marker, walk back to the chair, and sit down.

The $10 \mathrm{~m}$ walk test (10MWT) was performed by walking $10 \mathrm{~m}$ for the gait speed ${ }^{14)}$. The participants were asked to walk as fast and as safely as they could.

Twelve patients fulfilled the criteria and voluntarily agreed to participate in this study. The participants were randomly assigned to an experimental $(n=6)$ or control group $(n=6)$. The intervention comprised 4 weeks of inpatient treatment. Both groups received walking training for 30 minutes a day, 5 times a week for 4 weeks. Participants in the experimental group performed BAT for 20 minutes using the method of Lindvall et $\mathrm{al}^{3)}$. The subjects participated with bare feet to ensure contact with the floor during training. The expectation was that participants would experience physical awareness of body movement, and would learn how to integrate the movement. Movements were performed sitting and standing. To practice optimal alignment while sitting, a pillow wedge was used, and participants were not permitted to lean against the backrest. The participants were asked to be aware of changes in body tension. Stability limits were experienced by shifting body weight forward, backward, left, and right, until a sense of balance was achieved. In standing, the center line was perturbed by twisting around the center line with the arms lightly swinging.

Descriptive statistics were used to summarize baseline data. Categorical variables (gender, side of stroke) were compared between groups using Fisher's exact test. Between-group comparisons of baseline characteristics were performed using the Mann-Whitney U-test. Within-group comparisons of pre- and post-test values in each group were made using the Wilcoxon signed rank test, and between-group comparisons for post-test values were performed using the Mann-Whitney U-test. The significance level used was $\mathrm{p}<0.05$. 
Table 2. Descriptive measurements

\begin{tabular}{lcccc}
\hline & \multicolumn{2}{c}{ Experimental group $(\mathrm{n}=6)$} & \multicolumn{2}{c}{ Control group $(\mathrm{n}=6)$} \\
\hline & Pretest & Posttest & Pretest & Posttest \\
\hline BBS (scores) & $42.7 \pm 2.6^{\mathrm{a}}$ & $49.8 \pm 2.7^{*+}$ & $42.0 \pm 2.1$ & $46.3 \pm 2.2^{*}$ \\
TUG (seconds) & $18.9 \pm 1.1$ & $17.5 \pm 0.7^{*+}$ & $19.8 \pm 1.6$ & $18.8 \pm 1.2^{*}$ \\
10MWT (m/s) & $0.44 \pm 0.03$ & $0.55 \pm 0.03^{*}$ & $0.48 \pm 0.03$ & $0.53 \pm 0.04^{*}$ \\
\hline
\end{tabular}

${ }^{\mathrm{a}}$ Means $\pm \mathrm{SD}$

*Significant difference within group. ${ }^{+}$Significant difference between groups.

BBS: berg balance scale; TUG,: timed up and go; 10MWT: 10-meter walk test

The pretest was performed before the intervention, and the posttest was performed after 4 weeks.

The significance of differences was accepted for values of $\mathrm{p}<0.05$.

\section{RESULTS}

All the participants completed the entire study. There were no significant group differences in gender, paretic side, age, weight, height, time after stroke, BBS, TUG, and 10MWT before the intervention (Table 1). After the intervention, both groups showed significant differences compared with before the intervention in the BBS, TUG, and 10MWT (p<0.05) (Table 2). There were significant differences after intervention in the BBS $(\mathrm{z}=-2.093, \mathrm{p}=0.036)$ and TUG $(\mathrm{z}=-2.082, \mathrm{p}=0.037)$ between the two groups. There was no significant difference after intervention in the $10 \mathrm{MWT}(\mathrm{z}=-0.726, \mathrm{p}=0.468)$.

\section{DISCUSSION}

This study was performed to evaluate the therapeutic effect of BAT on balance and walking ability in patients with chronic stroke. Both groups showed significant changes after the intervention, and the experimental group showed more significant changes than the control group in BBS and TUG results. However, there was no significant change in the 10MWT. The findings of this study show that BAT improved balance ability in chronic stroke patients.

Balance depends on multiple sensory inputs and neuromuscular system interactions, and is crucial for stroke patient because falls often result from poor body awareness. In our study, BAT consisted of sensory stimulation and awareness of shifting body weight. As a result, balance ability improved. However, waking speed is related more to strength than to sensation. This was demonstrated in our study. Thus, walking speed did not show significant differences between groups ( $p>0.05$ )

Decreased balance ability may occur through disturbances of walking ability necessary for independent living in stroke patients ${ }^{15}$. In our study, the participants in the experimental group received BAT as an add-on to walking training for 20 sessions. The control group received only usual walking training. These results showed that BAT may be an effective method for improving balance ability.

In a study by Gyllensten et al. ${ }^{16}$, the participants receiving the intervention had improved body awareness, body acceptance, and self-efficacy. Our study showed similar results. In our study, the experimental group showed greater improvement in the BBS and TUG than the control group $(\mathrm{p}<0.05)$. These results have a positive aspect in chronic stroke patients. For independent living, stroke patients must be able to improve the ability to perform activities of daily living. These results seemed to indicate improved body awareness, and affected balance ability.

This study has some limitations. First, only a small number of hospital patients were recruited, so the data may not be representative of stroke patients as a whole. Second, there was no follow-up to measure the long-term effect, so the durability of the effect could not be determined. Thus, the results should be considered with caution.

In conclusion, this study investigated the effect of BAT on balance and walking ability in chronic stroke patients using the BBS, TUG, and 10MWT. It revealed that BAT positively affected the BBS and TUG, which measure balance. Thus, BAT is effective for the improvement of balance ability win chronic stroke patients.

\section{ACKNOWLEDGEMENT}

This research received no specific grant from any funding agency in the public, commercial, or not-for-profit sectors.

\section{REFERENCES}

1) Bang DH, Shin WS, Choi HS: Effects of modified constraint-induced movement therapy combined with trunk restraint in chronic stroke: A double-blinded randomized controlled pilot trial. NeuroRehabilitation, 2015, 37: 131-137. [Med- 
line] [CrossRef]

2) Weerdesteyn V, de Niet M, van Duijnhoven HJ, et al.: Falls in individuals with stroke. J Rehabil Res Dev, 2008, 45: 1195-1213. [Medline] [CrossRef]

3) Lindvall MA, Forsberg A: Body awareness therapy in persons with stroke: a pilot randomized controlled trial. Clin Rehabil, 2014, 28: 1180-1188. [Medline] [CrossRef]

4) Bang DH, Noh HJ, Cho HS: Effects of body awareness training on mild visuospatial neglect in patients with acute stroke: a pilot randomized controlled trial. J Phys Ther Sci, 2015, 27: 1191-1193. [Medline] [CrossRef]

5) Lord SE, Rochester L: Measurement of community ambulation after stroke: current status and future developments. Stroke, 2005, 36: 1457-1461. [Medline] [CrossRef]

6) Michael KM, Allen JK, Macko RF: Reduced ambulatory activity after stroke: the role of balance, gait, and cardiovascular fitness. Arch Phys Med Rehabil, 2005, 86: 1552-1556. [Medline] [CrossRef]

7) Bang DH, Shin WS, Kim SY, et al.: The effects of action observational training on walking ability in chronic stroke patients: a double-blind randomized controlled trial. Clin Rehabil, 2013, 27: 1118-1125. [Medline] [CrossRef]

8) Bang DH, Shin WS, Noh HJ, et al.: Effect of unstable surface training on walking ability in stroke patients. J Phys Ther Sci, 2014, 26: 1689-1691. [Medline] [CrossRef]

9) van de Port IG, Wood-Dauphinee S, Lindeman E, et al.: Effects of exercise training programs on walking competency after stroke: a systematic review. Am J Phys Med Rehabil, 2007, 86: 935-951. [Medline] [CrossRef]

10) Eriksson EM, Möller IE, Söderberg RH, et al.: Body awareness therapy: a new strategy for relief of symptoms in irritable bowel syndrome patients. World J Gastroenterol, 2007, 13: 3206-3214. [Medline] [CrossRef]

11) Hedlund L, Gyllensten AL: The experiences of basic body awareness therapy in patients with schizophrenia. J Bodyw Mov Ther, 2010, 14: 245-254. [Medline] [CrossRef]

12) Blum L, Korner-Bitensky N: Usefulness of the Berg Balance Scale in stroke rehabilitation: a systematic review. Phys Ther, 2008, 88: 559-566. [Medline] [CrossRef]

13) Podsiadlo D, Richardson S: The timed "Up \& Go": a test of basic functional mobility for frail elderly persons. J Am Geriatr Soc, 1991, 39: 142-148. [Medline] [CrossRef]

14) van Loo MA, Moseley AM, Bosman JM, et al.: Test-re-test reliability of walking speed, step length and step width measurement after traumatic brain injury: a pilot study. Brain Inj, 2004, 18: 1041-1048. [Medline] [CrossRef]

15) Bang DH, Shin WS, Choi SJ, et al.: Comparison of the effect of weight-bearing and non-weight-bearing positions on knee position sense in patients with chronic stroke. J Phys Ther Sci, 2015, 27: 1203-1206. [Medline] [CrossRef]

16) Gyllensten AL, Hansson L, Ekdahl C: Outcome of basic body awareness therapy. A randomized controlled study if patients in psychiatric outpatient care. Adv Physiother, 2003, 5: 179-190. [CrossRef] 